\title{
Response surface methodology based optimization of operating parameters of variable compression ratio C.I. engine fuelled with diesel-fish oil blends for minimal emissions.
}

\author{
Rasal Rushikesh $\mathbf{M}^{*}$ and Shelke Digvijay B. \\ ${ }^{1}$ Dr. D. Y. Patil School of Engineering Academy, Talegaon-Ambi, Savitribai Phule Pune University, India \\ Accepted 15 June 2016, Available online 20 June 2016, Special Issue-5 (June 2016)
}

\begin{abstract}
Rapid decline in conventional hydrocarbon fuel reservoirs is forcing researchers all over the globe to hunt for alternatives for these hydrocarbon fuels. Fish oil extracted from discarded body parts of fish like head, tail, fins, etc. has shown promising results on a fixed compression ratio engine. Lot of studies regarding optimization of fish oil extraction methods are reported in the literature. However no study related to optimization of combustion parameters of diesel engine fueled with fish oil is reported in the literature. This paper presents the same study at three blends of fish oil viz. B15 (15\% Fish oil+85\% Diesel), B30 (30\%Fish oil+70\% Diesel), B45 (45\% Fish oil +55\% Diesel). Together with fish oil blends compression ratio, injection timing and load are the parameters varied in the experimentation. Compression ratio is varied from 15 to 18, injection timing is varied from $20^{\circ}$ BTDC to $26^{\circ} B T D C$, and load is varied from $1 / 4^{\text {th }}$ to full load. Experimentation is carried out as per response surface methodology from concept of design of experiment. $\mathrm{HC}, \mathrm{CO}, \mathrm{CO}_{2}$ and $\mathrm{NOx}$ are the combustion parameters kept under observation. A regression model is also postulated for each mentioned combustion parameters to predict them at different levels of input parameters. Model is validated by performing ANOVA. Significance of each input parameter on responses is studied through mean effect plots. Interaction effects between input parameters and various fish oil blends on responses are studied with the help of contour plots and commented in the paper. Further optimization of input parameters is carried out with composite desirability approach. The entire experimentation is confirmed with 95\% confidence interval. Compression ratio 15:1, injection advance $21^{\circ}$ BTDC and load $3 \mathrm{~kg}$ and $22.5 \%$ fish oil blend were found to be optimal values in the test engine of $3.5 \mathrm{kw}$ at $1500 \mathrm{rpm}$.
\end{abstract}

Keywords: Fish oil, Emission, Design of Experiment (DoE), Response surface mothod, Parametric optimization.

\section{Introduction}

The energy problems caused by the progressive depletion of fossil fuel sources, the research for alternative fuels from renewable sources is in growing demand (Gislaine Iastiaque Martins, et al, 2015). Numbers of different fuels were tested from the begining of the idea of alternative fuels. These fuels are used for various applications like traditional boilers, furnaces, etc (Fernando Preto, et al, 2008). The cultivated land is limited therefore growing seed oil plants to fulfill the requirement of food and biodiesel is very difficult (Cherng-Yuan Lin, Rong-Ji Li, 2009). Therefore experimentation on the use of fish oil as fuel additive or substitute to conventional diesel is started in the recent past. Several tons of fish waste comes out from fishing industry daily which goes for making fish food and more is wasted. The fish oil contains approximately $90 \%$ of the energy content of diesel fuel

*Corresponding author: Rasal Rushikesh M and is easy to process into biodiesel fuels, this clean burning source of bio-oil/biodiesel can be used to reduce dependence on imported fuel and improve air quality within the region (Sharanappa Godiganur, et al, 2010).

The research on the impact of the transesterification methods on the production of biodiesel and its properties, including temperature, molar ratio methanol to oil and reaction time and its optimization is done in the research (Pedro J, et al, 2014). The oil is extracted from discarded parts of marine fishes of mixed species were refined in different steps and afterwards it is tranesterified to convert it into biodiesel and the performance and emission characteristics were studied in research (Cherng-Yuan Lin, Rong-Ji Li, 2009).

The study was also carried out by pyrolysis of fish oil by a continuous pyrolysis pilot plant where $\%$ of biodiesel was obtained at constant temperature of $525^{\circ} \mathrm{c}$ (V.R. Wiggers, et al, 2009). The effect of addition of catalyst on trans- esterification methods were studied and the output and the properties were 
compared with canola oil and lard (In Kwon Hong,et al, 2013). Usage of biofuels mixtures with traditional fuels or usage of pure biofuels needs experimental as well as numerical testing of their influences (or effects) on engine operating conditions and emission formation. Experimental investigation is usually quite expensive and time-consuming and therefore numerical simulations are commonly used when carrying out the parametric studies of biofuels influences on engines operating conditions, combustion process and emission formations. In (Pedro J. Garcia-Moreno, et al, 2014) paper optimization of production of fish oil biodiesel is done by fitting quadtratic model and surface response methodology which resulted into higher yield of biodiesel. The pongamia seeds biodiesel is used to study the effect of injection system parameters such as injection pressure, injection timing and nozzle tip protrusion on the performance and emission characteristics of a twin cylinder water cooled naturally aspirated CIDI engine. Response surface methodology is used to predict the response parameters (M. Pandian, et al, 2011). The experimentation was carried out on heavy duty diesel engine with $25 \%, 50 \%$ and $75 \%$ biodiesel blends by varying the engine speed from $1360 \mathrm{rpm}$ to $2000 \mathrm{rpm}$, the combustion, performance and emission parameters were studied experimentally and numerically by AVL Boost simulation software (Luka Lesnik, et al, 2014). In the experimentation carried by varying the load on the engine it is found that the $\mathrm{HC}, \mathrm{CO}$ and $\mathrm{NO}_{\mathrm{x}}$ emissions reduced with marginal increase in $\mathrm{CO}_{2}$ and smoke (G. Sakthivel, et al, 2014). The exhaust gas recirculation method was also used to improve the emission parameters of fish oil biodiesel along with the addition of oxygenate and it is found that there was reduction of $\mathrm{CO}$ by $91 \%, \mathrm{CO}_{2}$ by $62 \%$ and $\mathrm{NO}_{\mathrm{x}}$ by $92 \%$ (C. Swaminathan, J. Sarangan, 2012). The tests were conducted on anchovy fish oil at full load condition and speed is varied from $1000 \mathrm{rpm}$ to $2500 \mathrm{rpm}$, it is found that torque and power decreased by $4 \%$ and specific fuel consumption increased by $4.9 \%$, on the other hand emission parameters reduced considerably (Rasim Behcet, 2011). The optimization is done with two different biodiesels was done using response surface methodology at full load and constant speed of 2200 rpm and the optimum concentration of each component was 65.5 vol.\% diesel, 23.1 vol.\% n-butanol and 11.4 vol.\% cotton oil (Alpaslan Atmanl, et al, 2015). Thermodynamic model analysis of biodiesel with the help of Taguchi's optimization method to determine the optimum engine design parameters and operating parameters (T. Ganapathy. et al, 2009).

\section{Materials and methods}

\subsection{Fuel preparation}

There is abundant fish waste in local fish market. Waste fish oil coming from different industries is collected and primary filtration is done to remove dirt and other suspended particles present in the raw fish oil. Then the oil is kept to settle down to see any impurity is left behind. Then the chemical process of conversion of the raw fish oil into the fish oil biodiesel is started. At first the raw fish oil is poured into the system with a catalyst. The water content present in the fish oil led to formation of free fatty acids and triglyceride hydrolysis as the reaction temperature increases to higher value. The free fatty acid neutralizes the catalyst and hence soap formation occurs. The fish oil reaction with methanol under the presence of catalyst helps to form glycerin and methyl esters. This process for making biodiesel is comparatively simple. This process is knows as transesterification of fish oil. For this test process, the catalyst i.e. potassium hydroxide (1\%oil weight) and alcohol is mixed on the volume basis with the fish oil in the ratio of $1: 4$. As the waste fish oil from industries is used for the production of biodiesel, the color of resulting mixture was dark brown in the beginning of the reaction and then it was turned into a light brown color during the different phases of the reaction process. The reaction is conducted for $2 \mathrm{hr}$ at the temperature of $60^{\circ} \mathrm{C}$ at an agitation speed of $300 \mathrm{rpm}$ by keeping the pressure at ambient pressure. Biodiesel produced contains no sulfur or particular matter that results to air pollution. After getting the fish oil biodiesel from the above process it is mixed with the conventional diesel on volume basis to form blends as follows B15\% (15\% fish oil + 85\% diesel), B30\%(30\% fish oil $+70 \%$ diesel), B45\% (45\% fish oil $+55 \%$ diesel).

Table 1 Properties of fuel

\begin{tabular}{|c|c|c|c|c|c|}
\hline \multirow{2}{*}{$\begin{array}{c}\text { Sr } \\
\text { no }\end{array}$} & Test description & Diesel & \multicolumn{3}{|c|}{ Fish oil } \\
\cline { 3 - 6 } & $\mathrm{B} 00 \%$ & $\mathrm{~B} 15 \%$ & $\mathrm{~B} 30 \%$ & $\mathrm{~B} 45 \%$ \\
\hline 1 & Density (gm/cc) & 0.830 & 0.834 & 0.841 & 0.844 \\
\hline 2 & $\begin{array}{c}\text { Calorific } \\
\text { value(MJ/Kg) }\end{array}$ & 42.5 & 42.2 & 41.79 & 41.35 \\
\hline 3 & Cetane no. & 49 & 49.7 & 49.99 & 50.1 \\
\hline 4 & $\begin{array}{c}\text { Viscosity } \\
\text { (mm2/sec) }\end{array}$ & 2.7 & 2.9 & 3.1 & 3.46 \\
\hline 6 & Flash Point $\left({ }^{\circ} \mathrm{c}\right)$ & 64 & 88 & 96 & 111 \\
\hline 7 & Fire Point $\left({ }^{\circ} \mathrm{c}\right)$ & 71 & 92 & 102 & 117 \\
\hline
\end{tabular}

\subsection{Equipments and materials}

The experiments are carried on single cylinder water cooled naturally aspirated direct injection compression ignition engine whose specifications are prescribed in Table 2

Table 2 Engine specifications

\begin{tabular}{|c|c|}
\hline Number of cylinders & 1 \\
\hline Type & 4 Stroke, Multifuel, Water cooled \\
\hline Capacity & $661 \mathrm{cc}$ \\
\hline Stroke length & $110 \mathrm{~mm}$ \\
\hline Bore diameter & $87.5 \mathrm{~mm}$ \\
\hline Power & $3.5 \mathrm{~kW}$ at $1500 \mathrm{rpm}$ \\
\hline Compression ratio range & $12: 1$ to $18: 1$ \\
\hline Injection variation & 0o to $26^{0}$ Before top dead centre \\
\hline
\end{tabular}




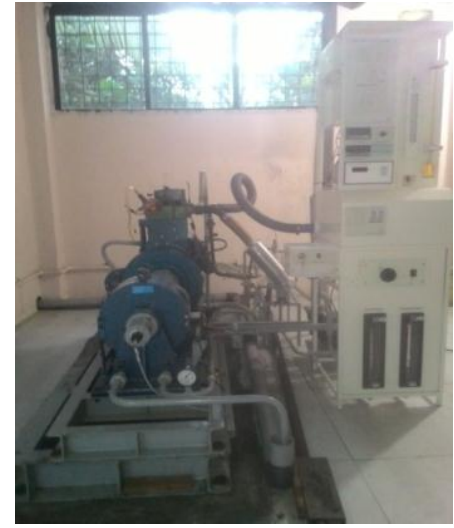

Fig.1 Engine test setup

The engine test setup consists of Kirloskar TV1 fixed compression engine modified into variable compression ratio engine. The compression ratio is varied by tilting cylinder bock with respect to crank case. 1psi, Diaphragm stainless steel type \& hermetic sealed is used to measure the pressure inside the cylinder. A crank position sensor Make KublerGermany Model 8.3700.1321.0360 is placed at the end of the propeller shaft to measure the position of the crank. An eddy current dynamometer of AG10 Series designed for the testing of engines up to $400 \mathrm{~kW}$ is used to load the engine. An ICEngineSoft9.0 software developed by Apex innovations pvt. ltd. is used to record all the readings. The compression ratio is varied from 15 to 18 in step of 1 . The injection timing can be altered by changing the position of fuel pump with respect to cam shaft. The injection timing is varied from $20^{\circ}$ BTDC to $26^{\circ}$ BTDC in step of 2 . The load can be varied by eddy current dynamometer. The load is varied from $3 \mathrm{~kg}\left(1 / 4^{\text {th }}\right)$ to $12 \mathrm{~kg}$ (full load). The mentioned levels of factors were selected because levels of emissions were significantly increasing beyond selected levels of input parameters. For the measurement of emission parameters five gas exhaust gas analyzer is used which can record $\mathrm{HC}, \mathrm{CO}, \mathrm{CO}_{2}, \mathrm{O}_{2}$ and NOx, the specifications of which are mentioned in Table 4.

Table 3 Five gas analyzer specifications

\begin{tabular}{|c|c|c|}
\hline Parameter & Measuring range & Resolution \\
\hline $\mathrm{HC}$ & $0-10000 \mathrm{ppm}$ & $1 \mathrm{ppm}$ \\
\hline $\mathrm{CO}$ & $0-9.999 \%$ & $0.00 \%$ \\
\hline $\mathrm{CO}_{2}$ & $0-20 \%$ & $0.01 \%$ \\
\hline $\mathrm{O}_{2}$ & $0-25 \%$ & - \\
\hline $\mathrm{NOX}$ & $0-5000 \mathrm{ppm}$ & $1 \mathrm{ppm}$ \\
\hline Repeatability & Less than $\pm 2 \% \mathrm{FS}$ & \\
\hline
\end{tabular}

\subsection{Response surface methodology}

The main objective of this work is to check the individual and mix effects of engine operating parameters on emission characteristics of C.I. engine fuelled with blends of fish oil using response surface methodology based design of experiments. The other objective is to find optimal values of compression ratio, injection timing, load and fish oil blends which might end in minimum emissions. For this type of multiobjective parametric optimization, concept of design of experiment is very helpful to evaluate emission characteristics of engine over the range of factors influencing response with minimum number of experiments. Response surface method of DoE (the concept of design of experiment) is used in the present study for modeling and analyzing the response parameters at different levels of factors that affects the responses. Table 4 presents experimental design matrix based on fractional factorial design of response surface methodology generated by "Design expert" (version 10.0) of stat ease, U.S., which contain fifty experimental runs. Required model points in the experimental design were 15. Additional 15 model points and 15 lack of fit points with 5 replicate points were added to support and make model more robust to the terms not included in the model.

Table 4 Experimental design

\begin{tabular}{|c|c|c|c|c|c|c|c|c|c|}
\hline Run & CR & IA & Load & Blend & $\mathrm{HC}$ & $\mathrm{CO}$ & $\mathrm{CO}_{2}$ & $\mathrm{O}_{2}$ & $\mathrm{NO}_{\mathrm{x}}$ \\
\hline 1 & 17 & 26 & 12 & 3 & 8 & 0.128 & 2.77 & 16.03 & 584 \\
\hline 2 & 16 & 22 & 6 & 1 & 13 & 0.079 & 2.93 & 16.59 & 481 \\
\hline 3 & 15 & 20 & 12 & 3 & 29 & 0.366 & 3.29 & 15.59 & 347 \\
\hline 4 & 16 & 20 & 12 & 2 & 30 & 0.309 & 2.92 & 16.26 & 215 \\
\hline 5 & 15 & 26 & 12 & 0 & 41 & 0.242 & 3.94 & 14.01 & 690 \\
\hline 6 & 15 & 22 & 6 & 2 & 13 & 0.109 & 3.01 & 16.22 & 401 \\
\hline 7 & 16 & 20 & 12 & 0 & 30 & 0.249 & 3.45 & 15.15 & 427 \\
\hline 8 & 18 & 20 & 3 & 2 & 15 & 0.09 & 3.05 & 16.3 & 466 \\
\hline 9 & 18 & 20 & 3 & 0 & 11 & 0.059 & 2.81 & 16.83 & 487 \\
\hline 10 & 15 & 20 & 12 & 3 & 29 & 0.366 & 3.29 & 15.59 & 347 \\
\hline 11 & 18 & 22 & 9 & 1 & 14 & 0.091 & 2.94 & 16.37 & 457 \\
\hline 12 & 15 & 26 & 3 & 0 & 31 & 0.196 & 3.2 & 15.72 & 299 \\
\hline 13 & 18 & 24 & 3 & 3 & 18 & 0.083 & 3.16 & 16.01 & 881 \\
\hline 14 & 18 & 22 & 3 & 1 & 18 & 0.082 & 2.93 & 16.52 & 558 \\
\hline 15 & 16 & 22 & 3 & 1 & 10 & 0.096 & 2.73 & 16.76 & 446 \\
\hline 16 & 15 & 24 & 3 & 3 & 22 & 0.163 & 3.21 & 15.97 & 300 \\
\hline 17 & 18 & 20 & 12 & 1 & 19 & 0.23 & 2.72 & 16.85 & 223 \\
\hline 18 & 16 & 26 & 6 & 2 & 14 & 0.104 & 3.07 & 16.06 & 575 \\
\hline
\end{tabular}




\begin{tabular}{|c|c|c|c|c|c|c|c|c|c|}
\hline 19 & 16 & 22 & 9 & 2 & 27 & 0.129 & 3.08 & 16.05 & 353 \\
\hline 20 & 17 & 24 & 6 & 1 & 11 & 0.087 & 3 & 16.35 & 647 \\
\hline 21 & 16 & 26 & 3 & 3 & 18 & 0.143 & 2.97 & 16.48 & 322 \\
\hline 22 & 18 & 26 & 3 & 2 & 17 & 0.082 & 3.1 & 16.1 & 896 \\
\hline 23 & 15 & 26 & 6 & 1 & 10 & 0.105 & 3.03 & 16.37 & 531 \\
\hline 24 & 17 & 20 & 6 & 3 & 11 & 0.068 & 3.16 & 15.95 & 598 \\
\hline 25 & 18 & 22 & 12 & 3 & 33 & 0.186 & 3.16 & 15.84 & 490 \\
\hline 26 & 18 & 20 & 9 & 2 & 18 & 0.109 & 3.18 & 15.86 & 393 \\
\hline 27 & 17 & 24 & 6 & 1 & 11 & 0.087 & 3 & 16.35 & 647 \\
\hline 28 & 15 & 22 & 3 & 0 & 18 & 0.09 & 2.71 & 17.06 & 354 \\
\hline 29 & 17 & 26 & 9 & 0 & 17 & 0.089 & 3.22 & 15.77 & 775 \\
\hline 30 & 17 & 24 & 9 & 3 & 43 & 0.132 & 3.92 & 14.39 & 829 \\
\hline 31 & 16 & 24 & 9 & 1 & 17 & 0.098 & 2.91 & 16.64 & 458 \\
\hline 32 & 15 & 24 & 3 & 1 & 13 & 0.144 & 3.04 & 16.25 & 465 \\
\hline 33 & 15 & 20 & 6 & 0 & 18 & 0.074 & 3.18 & 15.79 & 619 \\
\hline 34 & 18 & 24 & 6 & 0 & 17 & 0.06 & 2.94 & 16.58 & 658 \\
\hline 35 & 15 & 26 & 6 & 3 & 21 & 0.111 & 3.15 & 16.23 & 475 \\
\hline 36 & 16 & 24 & 12 & 2 & 30 & 0.262 & 2.92 & 16.18 & 309 \\
\hline 37 & 15 & 20 & 3 & 2 & 11 & 0.11 & 2.97 & 16.36 & 399 \\
\hline 38 & 17 & 20 & 3 & 3 & 15 & 0.94 & 3.15 & 15.98 & 550 \\
\hline 39 & 17 & 26 & 3 & 0 & 23 & 0.129 & 3.18 & 15.4 & 595 \\
\hline 40 & 16 & 22 & 6 & 1 & 13 & 0.079 & 2.93 & 16.59 & 481 \\
\hline 41 & 16 & 20 & 3 & 0 & 18 & 0.101 & 3.16 & 15.89 & 513 \\
\hline 42 & 15 & 20 & 12 & 1 & 27 & 0.283 & 2.95 & 16.5 & 222 \\
\hline 43 & 18 & 20 & 3 & 3 & 23 & 0.83 & 3.18 & 16.17 & 524 \\
\hline 44 & 18 & 26 & 12 & 0 & 20 & 0.094 & 2.74 & 16.72 & 647 \\
\hline 45 & 16 & 24 & 12 & 2 & 30 & 0.262 & 2.92 & 16.18 & 309 \\
\hline 46 & 18 & 26 & 3 & 2 & 28 & 0.089 & 3.24 & 15.78 & 896 \\
\hline 47 & 15 & 26 & 12 & 0 & 41 & 0.242 & 3.94 & 14.01 & 690 \\
\hline 48 & 15 & 24 & 9 & 1 & 24 & 0.126 & 3.07 & 16.4 & 418 \\
\hline 49 & 18 & 22 & 6 & 3 & 16 & 0.068 & 3.22 & 15.87 & 802 \\
\hline 50 & 17 & 22 & 9 & 0 & 13 & 0.047 & 2.91 & 16.58 & 542 \\
\hline
\end{tabular}

\section{Results and discussion}

\subsection{Analysis of the model}

The principal model analysis is based on the analysis of variance (ANOVA) which provides numerical information for the $\mathrm{P}$ value. The analysis of variance for different response parameters such as $\mathrm{HC}, \mathrm{CO}, \mathrm{CO}_{2}$ and NOx emissions are given in Table 4. Model found to be significant as the value of $P$ were less than 0.01 . Factors having $P$ value more than 0.1 suggest insignificance of input parameters over the output response. Cubic models for the responses are formed in terms of actual factors and are given below as equations 1 to 4 .

1] Cubic model for $\mathrm{HC}$ emissions

$\mathrm{HC}=18.39+1.37 \times \mathrm{CR}+4.56 \times \mathrm{IA}+16.31 \times \mathrm{LD}+11.07$

$\times \mathrm{BL}-2.69 \times \mathrm{CR} \times \mathrm{LD}+2.15 \times \mathrm{CR} \times \mathrm{BL}-2.40 \times \mathrm{IA} \times \mathrm{LD}$

$-2.46 \times \mathrm{IA} \times \mathrm{BD}-0.84 \times \mathrm{LD} \times \mathrm{BL}+1.10 \times \mathrm{CR}^{2}-5.90$

$\times \mathrm{IA}^{2}+3.43 \times \mathrm{LD}^{2}+4.83 \times \mathrm{BL}^{2}-4.05 \mathrm{CR}^{2} \times \mathrm{BL}-6.63$

$\times \mathrm{CR} \times \mathrm{BL}^{2}-5.83 \times \mathrm{IA}^{2} \times \mathrm{LD}-6.75 \times \mathrm{IA}^{2} \times \mathrm{BL}-5.72 \times$

$\mathrm{IA} \times \mathrm{LD}^{2}-5.28 \times \mathrm{L}^{2} \times \mathrm{B}-7.80 \times \mathrm{LD}^{3}$

2] Cubic model for $\mathrm{CO}$ emissions

$\mathrm{CO}=0.083-0.056 \times \mathrm{IA}+0.011 \times \mathrm{LD}+0.055 \times \mathrm{BL}-0.089$

$\times \mathrm{IA} \times \mathrm{BL}-0.055 \mathrm{LD} \times \mathrm{BL}+0.127 \times \mathrm{LD}^{2}$
3] Cubic model for $\mathrm{CO}_{2}$ emissions

$\mathrm{CO}_{2}=3.064+0.036 \times \mathrm{CR}+0.28 \times \mathrm{IA}+0.13 \times \mathrm{LD}+0.30 \times$ $\mathrm{BL}-0.11 \times \mathrm{CR} \times \mathrm{BL}-0.095 \times \mathrm{IA} \times \mathrm{BL}-0.034 \times \mathrm{LD} \times$ $\mathrm{BL}+0.02 \times \mathrm{IA}^{2}-0.18 \times \mathrm{LD}^{2}+0.21 \times \mathrm{BL}^{2}+0.10 \times \mathrm{CR}$ $\times \mathrm{LD} \times \mathrm{BL}-0.21 \times \mathrm{CR} \times \mathrm{BL}^{2}-0.23 \times \mathrm{IA}^{2} \times \mathrm{BL}-0.14$ $\times \mathrm{LD}^{2} \times \mathrm{BL}+0.19 \times \mathrm{LD} \times \mathrm{BL}^{2}-0.3 \times \mathrm{IA}^{3}-0.25 \times \mathrm{LD}^{3}$

3] Cubic model for $\mathrm{NO}_{\mathrm{X}}$ emissions

$$
\begin{aligned}
& \mathrm{NO}_{\mathrm{X}}=530.26+196.41 \times \mathrm{CR}+125.32 \times \mathrm{IA}-150.29 \times \mathrm{LD} \\
& +78.77 \times \mathrm{BL}+74.33 \times \mathrm{CR} \times \mathrm{IA}-68.32 \times \mathrm{CR} \times \mathrm{LD} \\
& +53.52 \times \mathrm{CR} \times \mathrm{BL}+43.38 \times \mathrm{IA} \times \mathrm{LD}-0.43 \times \mathrm{LD} \\
& \times \mathrm{BL}+7.77 \times \mathrm{CR}^{2}+42.87 \times \mathrm{IA}^{2}-138.61 \times \mathrm{LD}^{2} \\
& +74.11 \times \mathrm{BL}^{2}-59.93 \times \mathrm{CR} \times \mathrm{IA} \times \mathrm{LD}+52.65 \times \mathrm{CR}^{2} \\
& \times \mathrm{IA}+69.4 \times \mathrm{IA}^{2} \times \mathrm{LD}-98.22 \times \mathrm{IA}^{2} \times \mathrm{BL}-44.1 \\
& \times \mathrm{IA} \times \mathrm{LD}^{2}-63.48 \times \mathrm{IA} \times \mathrm{BL}^{2}+95.75 \times \mathrm{LD} \times \mathrm{BL}^{2} \\
& -105.44 \times \mathrm{CR}^{3}
\end{aligned}
$$

\subsection{Evaluation of model}

The stability of the all models developed was validated using Analysis of Variance (ANOVA) presented in Table 5 for the various responses. It is found that the models were significant with $\mathrm{p}$ values less than 0.0001 . The reference limit for $\mathrm{p}$ was chosen as 0.1 . The regression statistics goodness of fit $\left(\mathrm{R}^{2}\right)$ and the goodness of 
prediction (Adjusted $\mathrm{R}^{2}$ ) were shown in Table 5 for all the responses. The $\mathrm{R}^{2}$ value indicates the total variability of response after the significant factors taken into consideration. The Adjusted $R^{2}$ value accounts for the number of predictors in the model. Both the values show that the model fits the data very well.

Table 5 ANOVA for various responses indicating values of ' $p$ '

\begin{tabular}{|c|c|c|c|c|}
\hline Source & $\mathrm{HC}$ & $\mathrm{CO}$ & $\mathrm{CO}_{2}$ & NOX \\
\hline Model & $<0.0001$ & $<0.0001$ & $<0.0001$ & $<0.0001$ \\
\hline CR & - & - & - & $<0.0001$ \\
\hline IA & 0.0209 & 0.0243 & 0.0061 & $<0.0001$ \\
\hline LD & 0.0002 & - & - & $<0.0001$ \\
\hline BL & 0.0004 & 0.0282 & $<0.0001$ & $<0.0001$ \\
\hline IA-BL & 0.0378 & 0.0038 & 0.004 & - \\
\hline CR-BL & - & - & 0.008 & $<0.0001$ \\
\hline BL $^{2}$ & 0.0071 & - & $<0.0001$ & $<0.0001$ \\
\hline
\end{tabular}

Table 6 Response surface model evaluation

\begin{tabular}{|c|c|c|c|c|}
\hline Model & $\mathrm{HC}$ & $\mathrm{CO}$ & $\mathrm{CO}_{2}$ & $\mathrm{NOx}$ \\
\hline mean & 20.34 & 0.17 & 3.09 & 511.82 \\
\hline $\begin{array}{c}\text { std. } \\
\text { deviation }\end{array}$ & 4.67 & 0.13 & 0.12 & 39.8 \\
\hline $\begin{array}{c}\text { model } \\
\text { degree }\end{array}$ & cubic & cubic & cubic & cubic \\
\hline $\mathrm{R}^{2}$ & 0.8269 & 0.4805 & 0.8671 & 0.7916 \\
\hline Adj R & 0.7075 & 0.408 & 0.79 & 0.9485 \\
\hline Pred R & 0.3529 & 0.2301 & 0.5674 & 0.8825 \\
\hline
\end{tabular}

3.3 Interactive effects of Compression ratio (CR) and fish oil blend $(B L)$

The interactive effects of compression ratio and fish oil blends on $\mathrm{HC}, \mathrm{CO}_{2}$ and NOx are shown in figure 2 to 4 .

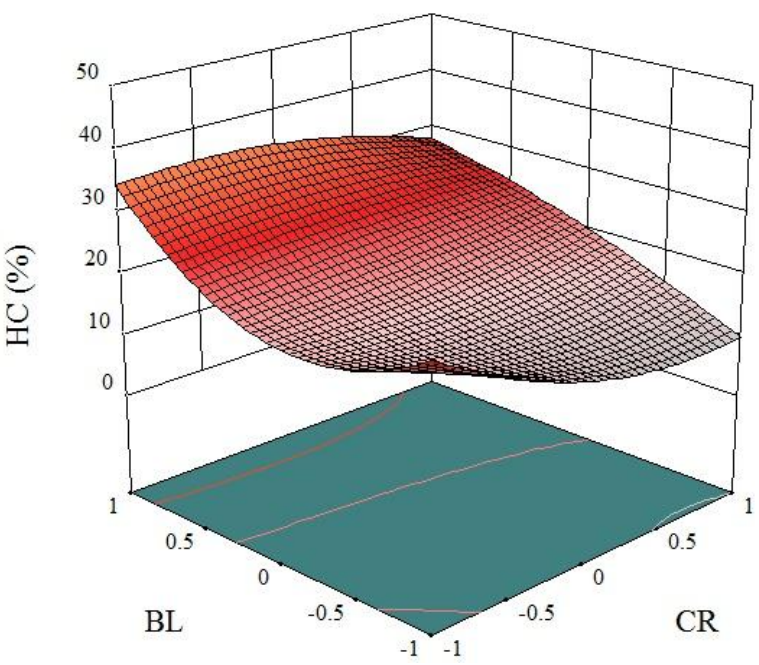

Fig.1 Interaction effect of Compression ratio and fish oil blend on $\mathrm{HC}$

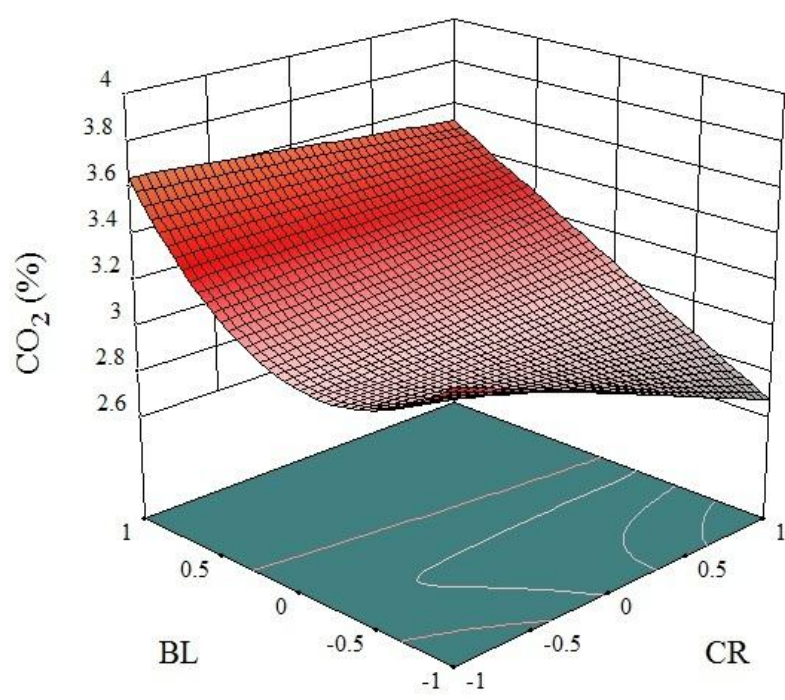

Fig.3 Interaction effect of Compression ratio and fish oil blend on $\mathrm{CO}_{2}$

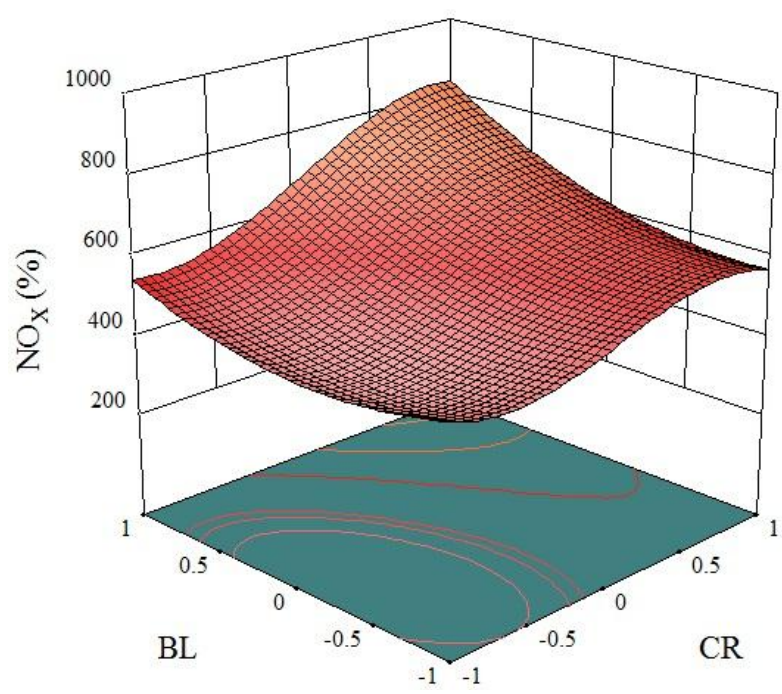

Fig.4 Interaction effect of Compression ratio and fish oil blend on NOx

At a given compression ratio as $\%$ of fish oil blend increases the values of $\mathrm{HC}, \mathrm{CO}_{2}$ and $\mathrm{NOx}$ decreases up to certain limit and again starts increasing towards higher $\%$ of fish oil blends. At given \% of fish oil blend values of $\mathrm{HC}$ and $\mathrm{CO}_{2}$ decreases whereas NOx increases with increase in compression ratio. Therefore in order to reduce $\mathrm{HC}, \mathrm{CO} 2$ and $\mathrm{NOx}$ it is always better to run the engine at lower compression ratio and fish oil blends.

3.4 Interactive effect of Injection Advance (IA) and Fish oil blends

The interactive effects of injection timing ratio and fish oil blends on $\mathrm{HC}, \mathrm{CO}$ and $\mathrm{CO}_{2}$ are shown in figure 5 to 7 . On lower side of injection timing the HC values increases with increase in \% of fish oil however on higher side of injection timing slight decrease in $\mathrm{HC}$ values is observed. On lower side of injection timing with increase in \% of fish oil blend CO \% increases and 
on the higher side of injection timing CO\% decreases with increase in $\%$ of fish oil blends. In case of $\mathrm{CO}_{2}$ at a given $\%$ of fish oil blend with increase in the injection timing the $\mathrm{CO}_{2} \%$ decreases in the beginning and then goes on increasing. Again at higher injection timing $\mathrm{CO}_{2}$ $\%$ decreases with increase in $\%$ of fish oil blend.

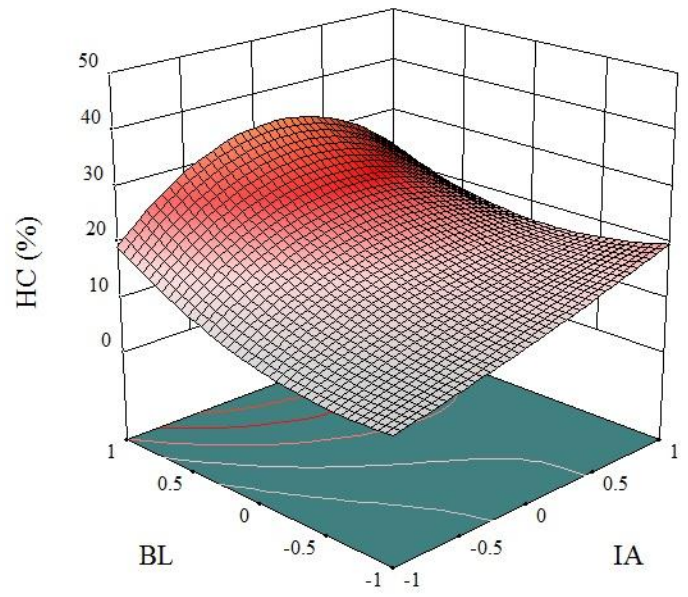

Fig.5 Interaction effect of Injection advance and fish oil blend on $\mathrm{HC}$

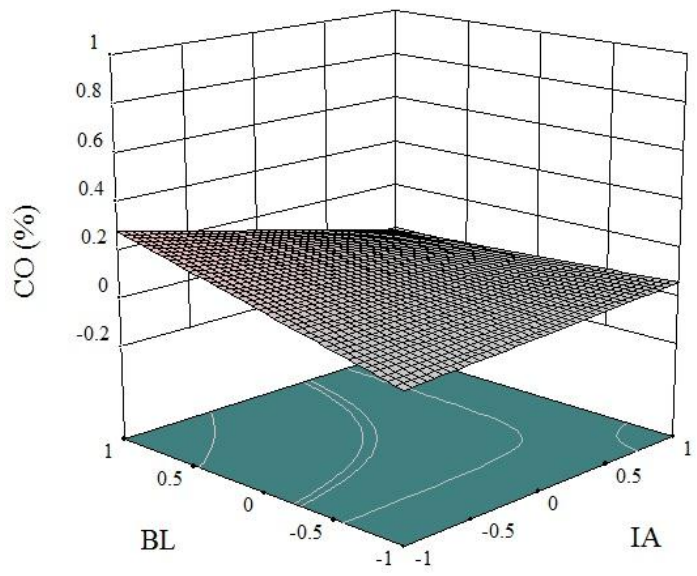

Fig.6 Interaction effect of Injection advance and fish oil blend on $\mathrm{CO}$

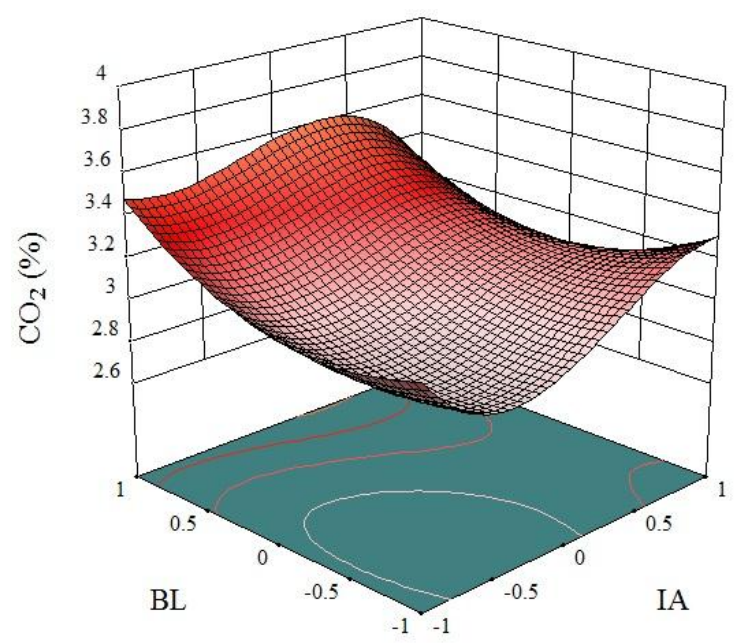

FIg.7 Interaction effect of Injection advance and fish oil blend on $\mathrm{CO}_{2}$

\subsection{Interactive effect of Load (LD) and Fish oil blend}

The interactive effects of load and fish oil blends on CO are shown in figure 8 . At a given $\%$ of fish oil blend as load goes on increasing $\mathrm{CO} \%$ decreases in the beginning and at higher load $\mathrm{CO} \%$ increases rapidly. At a given load with increase in \% of fish oil blend $\mathrm{CO} \%$ increases. Therefore to have minimum CO\% it is better to run the engine at moderate load and low $\%$ of fish oil blend.

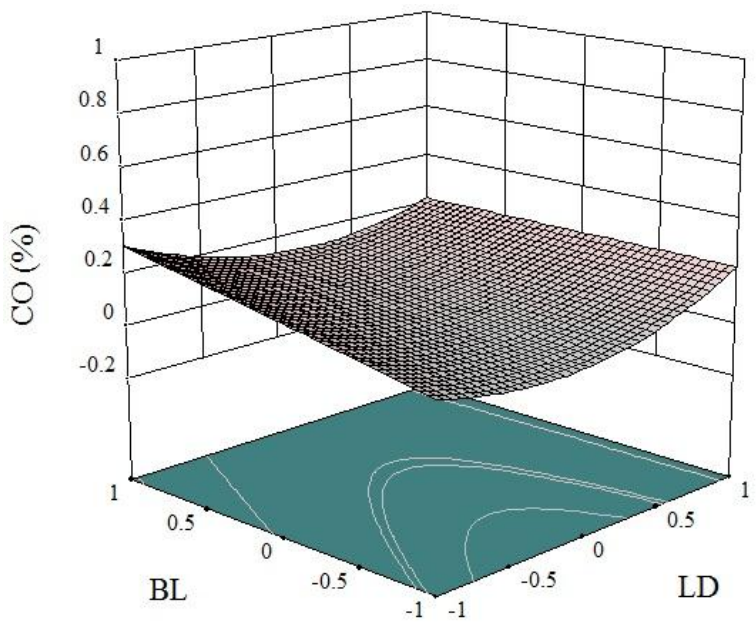

Fig.8 Interaction effect of Load and fish oil blend on CO

\section{Significance of input parameters on $\mathrm{HC}, \mathrm{CO}, \mathrm{CO}_{2}$ and NOx}

In order to identify the significance of input parameters on the mentioned emission parameters, main effect plots are plotted and are presented in figures 9 to12. Main effect plots for HC shows strong significance of load and fish oil blend on HC percentage in emission, however compression ratio and ignition timing are the insignificant factors. In order to have minimum $\mathrm{HC}$ emissions it is better to run engine at 17:1 compression ratio, $22^{\circ}$ BTDC injection advance, 6 $\mathrm{kg}$ load and 15\% fish oil and diesel blend. Main effect plot for Co shows significance of all input parameters except compression ratio. In order to have minimum CO emissions it's better to run engine at 17:1 compression ratio, $22^{\circ}$ BTDC injection advance, $6 \mathrm{~kg}$ load and no fish oil diesel blend. Main effect plots for CO2 shows highest significance of fish oil blend together with all other input parameters. In order to have minimum $\mathrm{CO} 2$ emissions it's better to run engine at $16: 1$ compression ratio, $22^{\circ} \mathrm{BTDC}$ injection advance, $3 \mathrm{~kg}$ load and 15\% fish oil diesel blend. At higher values of fish oil blending $\mathrm{CO} 2$ percentage increases though. Main effect plots for NOx shows significance of all input parameters. Compression ratio shows highest significance on NOx. With increase in fish oil blending NOx decreases up to $30 \%$ blending and then increases for $45 \%$ blend. In order to have minimum NOx emissions it's better to run engine at 16:1 compression ratio, 20 DBTDC injection advance, $12 \mathrm{~kg}$ load and 30\% fish oil diesel blend. Amongst selected input factors, 
fish oil blending has shown its significance on all the emission parameters.

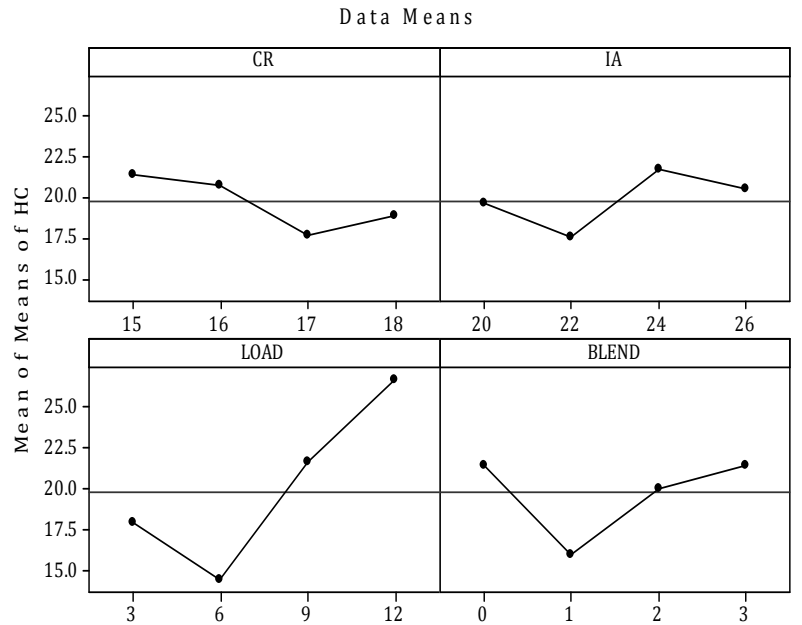

Fig.9 Mean of means of HC

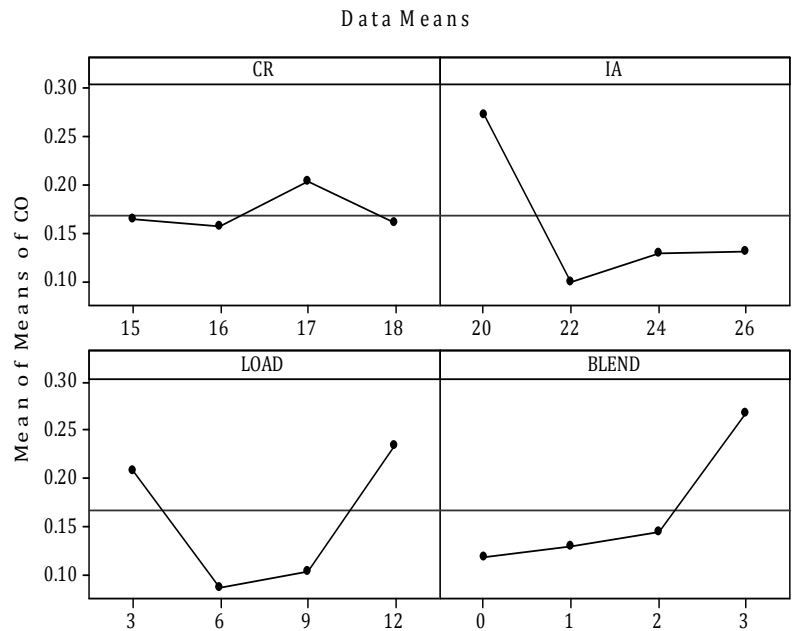

Fig.10 Mean of means of $\mathrm{CO}$

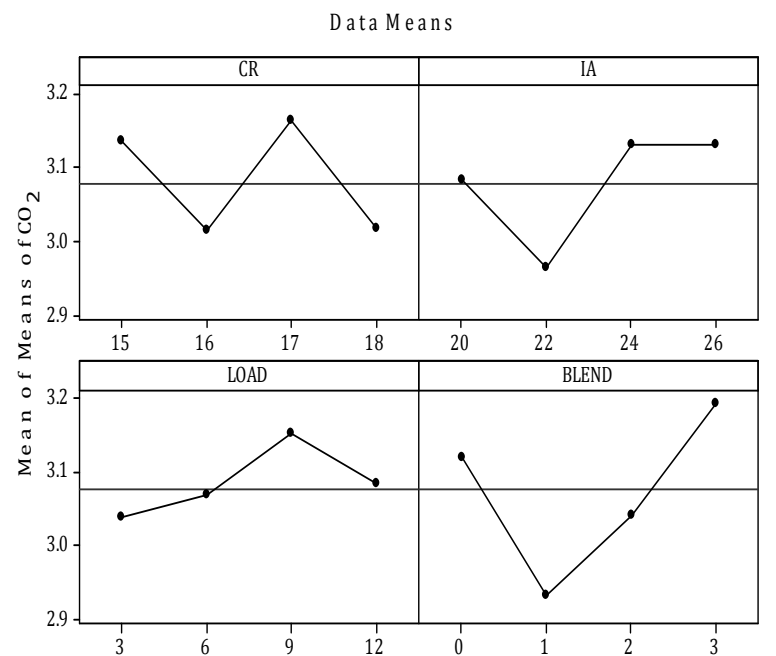

Fig.11 Mean of means of $\mathrm{CO}_{2}$

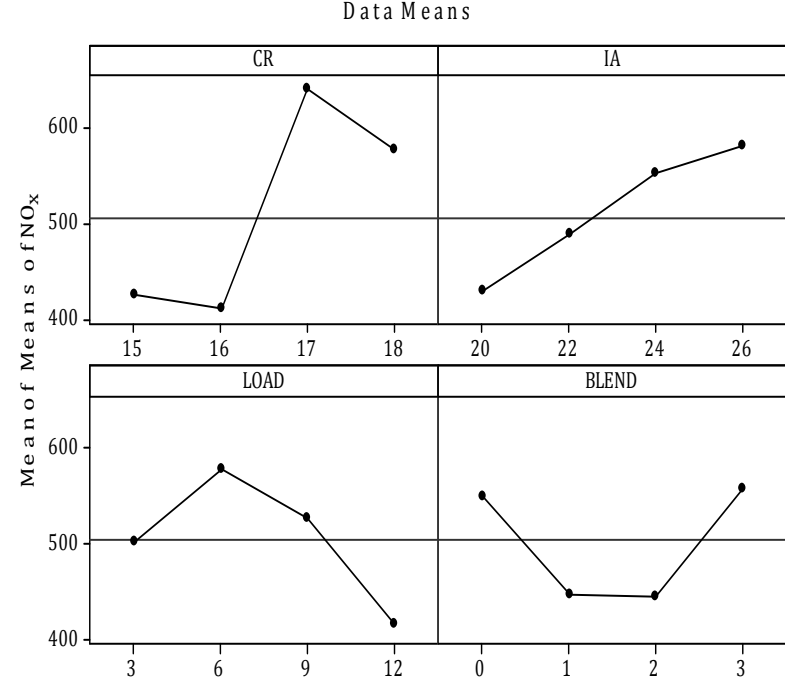

Fig.12 Mean of means of NOx

\section{Optimization}

The detailed discussion regarding interaction between various input parameters and significance study suggest different input parameters for minimum emission levels of $\mathrm{HC}, \mathrm{CO}, \mathrm{CO}_{2}$ and NOx. Since it's difficult to run engine at different levels for individual emission parameters it is decided to optimize levels of input parameters for minimal emissions. Composite desirability based approach found suitable in this regard (M. Pandian, et al, 2011). In desirability approach different best solutions were obtained and the solution with highest composite desirability is chosen for optimum levels of input parameters. The higher values of composite desirability justifies that the combination of input variables satisfies the goals defined for the responses very well.

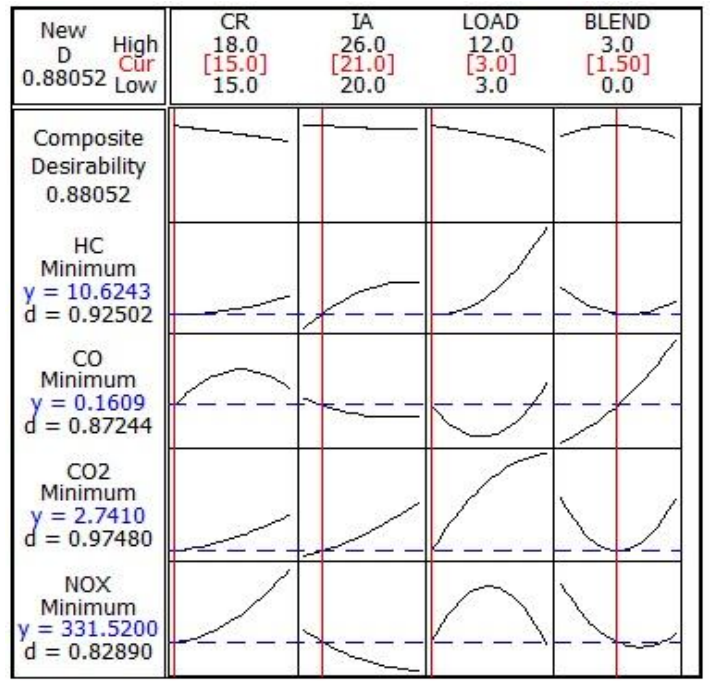

Fig.13 Optimizer plot

Figure- shows response optimizer plot for all the input parameters for minimum emission parameters. Highest desirability of 0.97 is obtained for $\mathrm{CO}_{2}$, 
followed by 0.92 for HC, 0.87 for $\mathrm{CO}$ and 0.83 for NOx. Composite desirability of 0.88 is obtained for CR $15: 1$, IA $21^{0}$ BTDC, Load $3 \mathrm{~kg}$ and fish oil blend $22.5 \%$. Confirmation experiment is conducted by setting the optimal values of compression ratio, injection timing, load and blend suggested by response optimizer plot. The fig.13 given below shows the predicted values of the input parameters Compression ratio, Injection advance, Load, Fish oil Blend for minimum emission parameters $\mathrm{HC}, \mathrm{CO}, \mathrm{CO}_{2}$ and $\mathrm{NO}_{\mathrm{x}}$ with their desirability.

Table 7 presents the comparison between modeled emission values and experimental emission values at CR 15, IA 210BTDC, Load 3kg, Fish oil blend 22.5\%.

Table 7 Predicted and experimental emissions

\begin{tabular}{|c|c|c|}
\hline Emission & Predicted & Experimental \\
\hline HC & 10.62 & 11 \\
\hline CO & 0.1609 & 0.11 \\
\hline CO2 & 2.74 & 2.97 \\
\hline NOx & 331.52 & 399 \\
\hline
\end{tabular}

\section{Conclusions}

The following are the conclusions drawn after performing the several tests in a single cylinder diesel engine by varying the compression ratio, injection timing, load and fish oil blend.

1) The statistical analysis helped to identify the significant parameters which are most influencing the emission characteristics. This experimental design remarkably saved the time required by minimizing the number of experiments to be performed and provided statistically proven models for all the responses.

2) Advancing the injection timing from $20^{\circ} \mathrm{BTDC}$ to $26^{0} \mathrm{BTDC}$ helped to reduce the $\mathrm{HC}, \mathrm{CO}$ and $\mathrm{CO}_{2}$.

3 ) Increasing the $\%$ of fish oil blend up to B2 (30\%) contributed to lower down the emission parameters $\mathrm{HC}, \mathrm{CO}, \mathrm{CO}_{2}$ and $\mathrm{NOx}$.

4) At moderate load all the blends of fish oil resulted in minimum $\mathrm{CO}$ emissions.

5) Desirability approach of the response surface method was the simplest approach. The desirability of 0.88 is obtained at optimum operating parameters viz. compression ratio 15 , injection timing $21^{\circ} \mathrm{BTDC}$, Load $3 \mathrm{~kg}$, fish oil blend $22.5 \%$ and the values of $\mathrm{HC}, \mathrm{CO}, \mathrm{CO}_{2}$ and $\mathrm{NOx}$ emissions are $10.62 \mathrm{ppm}, 0.16 \%, 2.74 \%$, $331.52 \mathrm{ppm}$ respectively.

6) The entire experimentation is carried out at $95 \%$ confidence interval

7) It is observed during performance characteristics analysis that amongst the selected input parameters load is most significant, the significance is so strong that it was difficult to identify effect of other input parameters on performance parameters like brake power, brake thermal efficiency and brake specific fuel consumption. In this work optimization of performance characteristics will be carried out at full load condition using same methodology.

\section{References}

Vanessa F. de Almeida, Pedro J. García-Moreno, Antonio Guadix, Emilia M. Guadix, (2015) Biodiesel production from mixtures of waste fish oil, palm oil and waste frying oil: Optimization of fuel properties. Fuel Processing Technology, 133, 152-160.

Gislaine Iastiaque Martins, Deonir Secco, Helton Aparecido Rosa, Reinaldo Aparecido Bariccatti, Bruna Dresch Dolci, Samuel Nelson Melegari de Souza, Reginaldo Ferreira Santos, Tiago Roque Benetoli da Silva, Flavio Gurgacz (2015), Physical and chemical properties of fish oil biodiesel produced in Brazil. Renewable and Sustainable Energy Reviews, 42, 154-157.

Mohammed Takase, Ting Zhao, Min Zhang, Yao Chen, Hongyang Liu, Liuqing Yang, Xiangyang Wu., ( 2015), An expatiate review of neem, jatropha, rubber and karanja as multipurpose non-edible biodiesel resources and comparison of their fuel,engine and emission properties. Renewable and Sustainable Energy Reviews, 43, 495-520.

Alpaslan Atmanlı, Bedri Yüksel, Erol Ileri, A. Deniz Karaoglan., (2015), Response surface methodology based optimization of diesel-n-butanol cotton oil ternary blend ratios to improve engine performance and exhaus emission characteristics. Energy Conversion and Management, 383-394.

G. Sakthivel, G. Nagarajan, M. Ilangkumaran, Aditya Bajirao Gaikwad, (2014), Comparative analysis of performance, emission and combustion parameters of diesel engine fuelled with ethyl ester of fish oil and its diesel blends. Fuel, $132,116-124$

Luka Lešnik, Jurij Iljaz, Aleš Hribernik, Breda Kegl, (2014), Numerical and experimental study of combustion, performance and emission characteristics of a heavy-duty DI diesel engine running on diesel, biodiesel and their blends. Energy Conversion and Management, 81, 534-546.

Pedro J. García-Moreno, Mohriam Khanum, Antonio Guadix, Emilia M. Guadix (2014), Optimization of biodiesel production from waste fish oil. Renewable Energy, 68, 618-624.

Kwon Hong, Jung Woo Park, Seung Bum Lee, (2013), Optimization of fish-oilbased biodiesel synthesis. Journal of Industrial and Engineering Chemistry, 19, 764-768.

D.C. Rakopoulos, (2013), Combustion and emissions of cottonseed oil and its bio-diesel in blends with either n-butanol or diethyl ether in HSDI diesel engine. Fuel, 105, 603-613.

R. Yahyaee, B.Ghobadian, G.Najafi, (2013), Waste fish oil biodiesel as a source of renewable fuel in Iran. Renewable and Sustainable Energy Reviews 17, 312-319.

Probir Kumar Bose, Madhujit Deb*, Rahul Banerjee, Arindam Majumder, (2013), Multi objective optimization of performance parameters of a single cylinder diesel engine running with hydrogen using a Taguchi-fuzzy based approach. Energy, 375-386.

Horng-Wen Wu, Zhan-Yi Wu, (2013), Using Taguchi method on combustion performance of a diesel engine with diesel/biodiesel blend and portinducting H2. Applied Energy, 362-370.

C. Swaminathan , J. Sarangan, (2012), Performance and exhaust emission characteristics of a CI engine fueled with biodiesel (fish oil) with DEE as additive. Biomass and bioenergy, 39, 168-174.

Horng-Wen Wu, Zhan-Yi Wu, (2012), Combustion characteristics and optimal factors determination with Taguchi method for diesel engines port-injecting hydrogen. Energy, 411-420.

Rasim Behçet, (2011), Performance and emission study of waste anchovy fish biodiesel in a diesel engine. Fuel Processing Technology, 92, 1187-1194.

Kian Fei Yee, Keat Teong Lee, Riccardo Ceccato, Ahmad Zuhairi Abdullah, (2011), Production of biodiesel from Jatropha curcas L. oil catalyzed by SO24 /ZrO2 catalyst: Effect of interaction between process variables. Bioresource Technology, 102, 4285-4289.

M. Pandian, S.P. Sivapirakasam, M. Udayakumar, (2011), Investigation on the effect of injection system parameters on performance and emission characteristics of a twin cylinder compression ignition direct injection engine fuelled with pongamia biodiesel-diesel blend usingresponse surface methodology. Applied Energy, 2663-2676.

Sharanappa Godiganur, Ch. Suryanarayana Murthy, Rana Prathap Reddy, (2010), Performance and emission characteristics of a Kirloskar HA394 diesel engine operated on fish oil methyl esters. Renewable Energy, 35, 355359.

Niraj Kumar, Varun and Anoop Kumar, (2010), Biodiesel as an alternative fuel for CI engines: environmental effect. Indian Journal of Science and Technology , 3, 602-606.

Jibrail Kansedo, Keat Teong Lee, Subhash Bhatia, (2009), Cerbera odollam (sea mango) oil as a promising non-edible feedstock for biodiesel production. Fuel, 88, 1148-1150

V.R. Wiggers, A. Wisniewski Jr., L.A.S. Madureira, A.A. Chivanga Barros, H.F. Meier, (2009), Biofuels from waste fish oil pyrolysis: Continuous production in a pilot plant. Fuel, 88, 2135-2141.

Cherng-Yuan Lin, Rong-Ji Li, (2009), Engine performance and emission characteristics of marine fish-oil biodiesel produced from the discarded parts of marine fish. Fuel Processing Technology, 90, 883-888.

T. Ganapathy, K. Murugesan, R.P. Gakkhar, (2009), Performance optimization of Jatropha biodiesel engine model using Taguchi approach. Applied Energy, 2476-2486.

Fernando Preto, Frank Zhang, Jinsheng Wang, (2008), A study on using fish oil as an alternative fuel for conventional combustors. Fuel, 87, 2258-2268. 